\title{
Viagens de Ida e de Volta ao Mundo das Sombras. Em Torno de Alguns Textos de Carlos Noriega Hope
}

\author{
Miriam V. Gárate ${ }^{(*)}$
}

Resumo: Em 1919, o crítico cinematográfico mexicano Carlos Noriega Hope viaja a Los Angeles, cidade na qual realiza uma série de entrevistas e de notas publicadas inicialmente na imprensa e logo reunidas em El mundo de las sombras, el cine por fuera y por dentro (1921). Alguns anos depois, vários aspectos relativos à "fábrica de sonhos" e ao star system hollywoodiano contidos nas matérias jornalísticas foram retomados pelo autor em narrativas ficcionais de tema cinematográfico. Este trabalho busca examinar as relações instauradas entre os dois conjuntos de textos, levando em consideração o impacto que exerce na vida social (pública e privada) a ascensão do novo espetáculo, bem como as peculiaridades do contexto histórico.

Palavras-chave: Crônica Cinematográfica, Literatura, México, Estados Unidos, Primeiras Décadas do Século XX.

Abstract: In 1919, Carlos Noriega Hope, a Mexican film critic, travels to Los Angeles, where he publishes a series of interviews in the print media, which were compiled in El mundo de las sombras, el cine por fuera y por dentro (1921). After some years, many aspects of his texts regarding the "dream factory" and the Hollywoodian star system were revisited in fictional narratives on cinema. This article intends to analyze the connections suggested by the two bodies of texts, as well as to study the impact of the "new spectacle" on social life, both public and private, not to mention the particularities of the historical context in which this process takes place.

Keywords: Film Reviews, Literature, Mexico, United States, Early XX-th/XXth Century.

(*) Docente do Departamento de Teoria Literária-IEL/Unicamp. E-mail: miriam_garate@yahoo.com.br. Recebido em 9.2.09 e aceito em 27.4.09. 
Em dezembro de 1919, o mexicano Carlos Noriega Hope (1896-1945) viaja a Los Angeles enviado por El Universal, jornal em que assumira, desde inícios daquele ano, a coluna de crônica cinematográfica intitulada Por las pantallas. As impressões desse "repórter curioso", segundo palavras do próprio autor, foram publicadas inicialmente no semanário El Universal Ilustrado e reunidas logo depois em El mundo de las sombras, el cine por fuera $y$ por dentro (1921). Trata-se, sustenta Ángel Miquel, do "primeiro livro sobre a nova arte escrito por um mexicano" (1995. p. 83$)^{(1)}$.

No que tange à nova arte naquele país, o período se caracteriza por algumas tentativas de produção local, pela introdução da cinematografia alemã, mas, principalmente, pelo firme avanço da cinematografia estadunidense em detrimento da italiana, favorita do público mexicano até então. Com efeito, superado o impacto inicial diante das primeiras vistas captadas pela "maravilha técnica" chamada cinematógrafo — impacto do qual deram testemunha, entre outros, Luis G. Urbina, José Juan Tablada e Amado Nervo ${ }^{(2)}$ —, o cinema opta predominantemente pelo caminho da narração. Numa primeira fase, a cinematografia francesa, porém mais ainda as "superproduções" italianas, com suas divas de gestos amplos e melodramáticos, usufruíram da preferência irrestrita dos espectadores; a passagem aos anos 20 é pautada pela progressiva hegemonia do cine norte-americano tanto no México quanto, de forma geral, na América Latina ${ }^{(3)}$. Nessa conjuntura, Carlos Noriega Hope,

(1) Agradeço a Ángel Miquel ter-me facilitado obras raras de Carlos Noriega Hope, como a acima citada. A redação deste artigo teria sido impossível sem sua generosidade.

(2) O eloquente oximoro "maravilha técnica" pertence ao poeta Luis G. Urbina (1864-1936), um dos primeiros cronistas das projeções efetuadas na capital a partir de 1896 (El cinematógrafo. El Universal de 23.8.1896). Essa apreensão científicofantástica dos poderes de um aparelho decididamente superior aos dispositivos óticos precedentes no que tange à duplicação do real verifica-se também em crônicas de Enrique Chávarri, Amado Nervo, José Juan Tablada. Nelas, deparamos com manifestações da seguinte ordem: "O dia que for possível unir o cinematógrafo ao fonógrafo, os mortos ressuscitarão, poderão ser evocados como nas sessões espíritas, poderão ser chamados da eternidade e ser obrigados a falar, a se mover, a retornar à vida; eles, que tão à vontade devem estar no país dos espectros. Qualquer um poderá ter seus mortos queridos gravados numa película fotográfica sistema Lumière e lançá-los, daí, por meio da lanterna mágica, à branca tela, para vê-los animar-se ao mesmo tempo em que o fonógrafo fala com a própria voz daqueles que existiram (...). O mundo avança, não há dúvidas; estamos a caminho da imortalidade" (CHÁVARRI, E. Charla de los domingos. El Monitor Republicano, 6.9.1896); "O cinematógrafo é o Zola do impossível” (TABLADA, J. J. México sugestionado. El espectáculo de moda. El Imparcial, 16.10.1896); "A morte foi vencida! Seguiremos vendo e ouvindo os seres que admiramos e amamos e será como se não se houvessem extinguido! Que o fantasma se movimente e fale graças ao sortilégio de uma fita e de? disco, ou que fale e se movimente graças a esse outro sortilégio da energia armazenada num corpo e que constitui a vida... tanto faz!" (NERVO, A. El mundo, 20.3.1899). Todas as citações do trabalho foram traduzidas para o português, e a tradução é de minha autoria.

(3) Aurelio de los Reyes (1993) refere a alguns indicadores desse processo ao mencionar a realização de uma série de concursos ao longo de 1920 destinados a escolher e premiar a "melhor fita" (El Heraldo de México) ou a "atriz favorita" do público (El Universal Ilustrado). No que diz respeito às fitas, os três primeiros lugares corresponderam a melodramas italianos, e o quarto, a uma fita de Mary Pickford; no que tange às atrizes, o primeiro lugar coube à francesca Bertini, o segundo, à Mabel Norman, o terceiro, à Pearl White, e o quarto, à Pina Menichelli. Como assinala o historiador: "o público duvidava na hora de escolher entre o cinema italiano e o norte-americano. Em maio, elegeu as atrizes norte-americanas, ao passo que, em agosto, as italianas, como o fizera nos tempos do senhor Carranza. Essas "quarteladas sentimentais" deviam-se aos vaivens da programação" (52-3). Todavia, o avanço irreversível do cinema estadunidense deixa suas marcas na imprensa: "Califórnia testemunhara a febre do ouro em meados do século XIX, no século XX, testemunhava a "febre do cinematógrafo", propiciando a história vulgar da vertiginosa ascensão e queda social por meio do cinema. Os mexicanos começaram a acreditar nessa quimera do ouro, nessa nova terra prometida. Miragem alimentada pela imprensa mexicana, cujas páginas começaram a difundir a moda norte-americana e impor o ideal de beleza emanado de Hollywood: Você tem rosto de estrela? (...) qualquer jovem que ambicione ser uma Mary Pickford pode determinar por meio dessa fórmula se é das poucas mulheres cujas feições possuem a medida fotográfica standard (de um "T")" (El 
defensor veemente da nova arte, bem como da "naturalidade expressiva" e do "realismo ambiente" das fitas norte-americanas - não necessariamente da qualidade de seus argumentos - viaja à capital do cinema. No decorrer de duas décadas e meia, a fantasia inicial de perpetuar esta vida para além da vida por meio do cinematógrafo foi deslocada pela fantasia de viver outra vida nesta vida graças ao cinema - em outras palavras: pelo desejo de levar uma vida de filme. Evidentemente, não é casual que muito cedo o novo espetáculo tenha sido associado a duas metáforas/dois processos: a viagem imaginária, o sonho fabricado $^{(4)}$. Mas não todos se contentam com sonhar/viajar na sala escura, durante a projeção. Há os que realmente viajam no intuito de materializar o sonho; há os que viajam com o propósito de olhar a fábrica, de examiná-la por fora e por dentro e comunicar essas visões ao público. A essa última classe pertence o "repórter curioso" Carlos Noriega Hope.

$* * *$

Assinalo alguns traços presentes nas crônicas jornalísticas, com o objetivo de examinar a relação instaurada entre os apontamentos do repórter e o discurso do autor de narrativas de tema cinematográfico, narrativas entre as quais vale mencionar El viejo amigo (1923), El honor del ridículo (1923) e Che Ferrati, inventor (1923), conto de Noriega que foi objeto de uma representação teatral em $1924^{(5)}$.

O marco das crônicas redigidas para El Universal é dado pela viagem à "capital do cinema", cidade na qual Noriega permanece cerca de 60 dias. Imediatamente após chegar a Los Angeles (o translado num moderníssimo trem e espécies de admiráveis "hotéis cidades" como o Alexandria são descritos em detalhe), Noriega faz sua primeira incursão num studio, o de Thomas H. Ince, acompanhado pelo amigo e compatriota Manuel Ojeda, que faz as vezes de um cicerone durante sua estada ${ }^{(6)}$ :

Universal Ilustrado, 27.5.1920) (56). Para uma abordagem historiográfica dos primeiros tempos do cinema no México cf., entre outros: Reyes, Aurelio de los (1981, 1986); Leal, Juan Felipe; Barraza, Eduardo; Flores Carlos (2002); Miquel, Ángel (2005).

(4) Hugo Mahuerhofer (1949) caracteriza a situação cinema, também denominada por outros autores dispositivo cinematográfico, a partir dos seguintes fatores copresentes na projeção de uma fita: isolamento do mundo exterior e de suas fontes de estímulo; b) alteração das sensações de tempo e de espaço; c) passividade física do espectador. Passividade, isolamento e alteração espaço-temporal combinam-se para dar forma a uma experiência que se constitui como cancelamento provisório da realidade imediata, como fuga voluntária desta e simultaneamente como entrada numa realidade imaginária cujo poder de ilusão, devido à força de presença da imagem fílmica e aos procedimentos inerentes à montagem clássica, é maior que o das representações teatral ou literária. A realidade, ao mesmo tempo excludente e íntima das duas "realidades" em jogo, a lógica de sua alternância e algumas de suas características permitiram postular muito cedo no âmbito das teorizações cinematográficas a associação com a dupla vigília/sonho, associação em que coube ao cinema um papel homólogo ao do segundo termo. Para uma abordagem mais recente dessas questões: cf. Rosset, Clément (2001).

(5) Além de seu trabalho constante como crítico cinematográfico e de sua produção de contos, Noriega Hope realizou um filme, rodado em 1921 e estreado em 1923: La gran noticia, também conhecido como Los chicos de la prensa. Produziu, ademais, alguns roteiros, entre os quais se destaca o da primeira versão sonora de Santa, filme baseado no romance homônimo de Federico Gamboa, cuja estreia deu-se em 1931.

(6) No item que leva o título Mexicanos en Hollywood, Aurelio de los Reyes (1993. p. 54-5) comenta: "Começou a falar-se com insistência dos mexicanos que tentavam em Hollywood uma carreira cinematográfica. De Manuel Ojeda — que levava vários anos por lá e interpretara papéis menores em várias fitas, além de ser correspondente cinematográfico de El Universal - disseram que havia sido nomeado presidente da Peruvian Film Company de Lima, onde iria "a fim de produzir (...) fotodramas sobre costumes e tradições locais” (Los cines artistas mexicanos en el extranjero. El Universal, 20.6.1920). José Vasconcelos concedeu a Elena Sánchez Valenzuela, atriz de Santa e de La Llaga, a bolsa que solicitara para estudar cinema em Hollywood; ela seria, ademais, correspondente de El Demócrata. William Duncan afirmou numa entrevista que tinha predileção pelos trabalhadores mexicanos de cinema, "gente de fácil compreensão e de valor temerário". 
O carro chegou às portas da Golwdyng, e timidamente fui atrás de meu amável cicerone até a sala de informações. Nunca em minha vida, senhoritas, vi um espetáculo mais desolador. Tanto é assim que me atrevo a odiar esse pequeno incidente, esse horrível incidente, que se apresentou a meus olhos como a primeira manifestação cinematográfica.

Na sala de espera à qual me refiro havia - sem exageração alguma - pelo menos três dezenas de garotas distribuídas em cadeiras e poltronas. Entrei e fiquei extasiado, porque todos os exemplares femininos valiam, realmente, o esforço de uma longa contemplação... Todas aguardavam algo. Olhei Ojeda e, ansiosamente, com enorme curiosidade, lhe perguntei:

- Manuel, por acaso, essas garotas são estrelas ou algo semelhante? Apresente-as a mim, por favor!

— Não, senhor, são "figurantes" que esperam pacientemente, talvez uma hora, talvez um dia ou uma semana, que alguém utilize os seus serviços no studio. Chegam sempre cedo e vão embora ao cair da tarde, sem que a impaciência as fatigue... Nesta cidade de 700 mil almas existem mais de 10 mil figurantes bonitas, jovens, talvez com intuição artística, que trabalham um ou dois dias na semana em diversos studios! Sem esperança de subir na vida, de atingir o cume.

Assim, me pareceu que nesse régio edifício de Goldwyn, existia um grande cartaz com as frases que vira o Dante no inferno, destinado a matar, para sempre, qualquer esforço e qualquer entusiasmo dos pobres ilusos, sejam homens ou mulheres, que sonham com o cinema (1921, p. 22-3).

Vale reter esse "pequeno", mas "horrível", "incidente" que "se oferece" ao repórter como "primeira manifestação cinematográfica" da qual faz um registro, apesar de o olhar driblá-lo para seguir em outra direção - em direção à "terra de maravilhas", ao "conto de fadas", ao mundo artificial e, no entanto, convincente dos sets:

Tudo o que escreva agora será um débil reflexo do que vi porque sou impotente para descrever essa terra de maravilha, esse lugar de conto de fadas. Basta dizer que ao sair me conduziram para as diversas construções provisórias ou sets, erguidos para a confecção das últimas fitas... Meu Deus! Estava numa rua artificial rodeado de prédios artificiais, com bondes elétricos (ou pelo menos isso me parecia) artificiais! Tinha acreditado falsamente na realidade dessa rua e, no fim, tudo era de cartão e de papier maché... E convenci-me ainda mais ao virar uma esquina e topar com outra rua... Era uma rua da antiga Inglaterra e eu me senti, nesses momentos, Oliver Twist a caminho

Sobressaíram-se Fernando Elizondo e Beatriz Domínguez; dessa última, se exibiu o seriado de dezoito 18 em 36 partes intitulado Las calaveras del terror (1920); ela morreria em Hollywood, meses depois de dançar com Rodolfo Valentino o famoso tango de Los cuatro jinetes del Apocalipsis. Fernando Elizondo monopolizou a atenção porque passou de humilde funcionário de ferrovia à "primeira estrela mexicana no firmamento de Hollywood". Foi ao México para contar sua história e exibir suas fitas". O panorama traçado pelo historiador interessa não somente por caracterizar o contexto em que ocorre a visita de Noriega, mas a presença, nesse horizonte histórico, de um fenômeno que será retomado em sua ficção: o dos mexicanos em busca de sucesso e de celebridade em Hollywood. 
do hospício. Mas viramos uma esquina e se ofereceram à minha visão uma choupana caindo aos pedaços, uns barracos, os restos de um barco... Este set - disse Ojeda sorrindo - representa uma ilha selvagem, a "Ilha do Tesouro"... E então veio rapidamente à minha imaginação todo o livro... Oh, poetas, artistas, literatos: por desgraça, vocês não conhecem um studio... Aqui, nestes lugares, sem telões, se reproduz ao ar livre qualquer paisagem criada pela imaginação de um escritor; pela primeira vez na história, o mundo das fantasias dos poetas, dos voos imaginativos dos romancistas... pode ser mostrado real e tangível, graças ao cinematógrafo... Poetas, artistas, literatos: a imaginação criadora de coisas belas foi vencida pela ciência, e Pégaso, em vez de remontar ao infinito, cavalga hoje por esta terra de maravilha...! Abençoado seja o cinematógrafo (1921. p. 24-6).

Viagens de diversa índole se justapõem nessa primeira crônica: a real, que conduz Noriega do México a Los Angeles num moderníssimo trem; a dos sets decorados, vinculada a um trajeto físico do sujeito pelas ruelas de papelão; a suscitada na mente do cronista e que dá lugar a um segundo trajeto imaginário - aquele que dista entre "a paisagem de papelão" e a descrita "pelo livro" — , concretizando as imagens da segunda graças à primeira. A Ilha do Tesouro finalmente torna-se "real" graças ao cinematógrafo.

Daqui em diante - a nota conclui com o encontro de Mabel Normand, a quem Noriega entrevista —, prevalecerá a visão dos milagres produzidos pela "terra de maravilhas", dos sonhos realizados por estrelas e cineastas de renome. Em sua maioria, os textos esboçam um retrato das personalidades entrevistadas e eventualmente uma biografia sumária na qual, como seria de se esperar, a constante é a escalada ou permanência no reduzido grupo dos eleitos. Desfilam, dessa forma, Schertzinger, o diretor que "fez" Mabel Norman (a crescente importância dessa classe profissional é constantemente sublinhada, bem como a dos publicitários), Charles Chaplin, William Hart, Al St. Jonhn, Edie Polo ("o único ator modesto" que Noriega conhece em Los Angeles), Alan Dwan, Tony Moreno (popular astro "latino" da época), May Allison, Douglas Fairbanks, Max Linder, Max Sennet, Jack Dempsey, Clara Kimbal Young (atriz extraordinariamente "culta" e "erudita" que fascina o jovem repórter).

É verdade que não tudo é da ordem da pura maravilha nessa série de notas. Embora não ocupem o centro da cena, as crônicas introduzem considerações de outro teor: mencionam-se números e custos (Schertzinger "ganha US\$2000,00 semanais", Los Angeles "produz 500 fotodramas todos os dias", reproduzir "um povoado madeireiro de Wisconsin num studio seria "mais barato" do que deslocar o elenco e a equipe); comentam-se estratégias para as quais confluem os aspectos técnicos e mercadológicos (filmar várias vezes uma mesma sequência destinada a públicos de diferentes latitudes, prática comum na qual Chaplin era exímio, segundo Noriega); revelam-se segredos de diversos aspectos (uma das notas se refere ao perigo dos atores de perder a visão por causa das luzes de mercúrio, outra, à altercação entre Antonio Moreno e Ojeda devido a uma entrevista deste último, supostamente prejudicial para a imagem "latina" do primeiro). Mas, apesar dessas observações, o tom que prevalece é o da empatia, ao passo que o olhar crítico, embora não subjugado por inteiro, é mantido sob controle. Essa atitude certamente decorre de uma clara percepção das várias demandas ou expectativas em jogo: as dos contratantes de Noriega, as do veículo 
para o qual escreve e do público ao qual se endereça e, finalmente, as do star system, ao qual consegue ter acesso sob a condição de aceitar regras tácitas. Ainda que não se deva descartar uma adesão genuína por parte do jovem enviado ao "mundo de maravilha" que se apresenta diante de seus olhos, não há dúvidas de que seu discurso se movimenta com a habilidade do equilibrista que sabe o que é possível dizer e onde, bem como o que convém calar.

Perpassando esse conjunto de crônicas, uma constante: a permanente menção ao México e aos mexicanos, aos clichês negativos que pululam (e o cinema estadunidense contribui a propagar), bem como o contrapeso representado pelas sistemáticas manifestações de simpatia de cada um dos entrevistados em relação a esse povo, à sua história, às suas paisagens. Mabel Norman se faz fotografar com Ojeda e Carlos Noriega Hope "para enviar a fotografia ao México", país onde vivera e do qual tem gratas lembranças (32); a senhora Frederics comenta que uma parte da fita em processo de filmagem transcorre no México e exprime sua satisfação porque nela "os mexicanos não serão os eternos bandidos" (p. 37-8); William Hart sustenta que o dia em que estiver em posse de uma "uma boa história baseada em assuntos mexicanos, na qual se mostrem as nobres qualidades desse país, será um dos mais felizes", pois deseja "filmar uma fita mexicana que seja do gosto dos mexicanos" (52); Douglas Fairbanks manifesta seu desejo de rodar no México um filme de tema histórico (59); Edie Polo, Tony Moreno, Charles Chaplin, May Allison, todos explicitam seu afeto pelo país (um mercado em expansão) ${ }^{(7)}$.

Para concluir a viagem por esse "mundo de maravilhas", uma anedota que retoma o "pequeno", mas "horrível", "incidente" do primeiro dia em Los Angeles. Poucas horas antes de partir, Noriega faz uma visita de despedida a Mabel Norman. Esta lhe pede que entreviste uma moça:

— Mister Mex — me diz Mabel —, não vá embora sem entrevistar uma moça. Quero que você a veja e escreva no México alguma coisa sobre sua personalidade. Não importa

\footnotetext{
(7) Desde o início da revolução, as relações entre México e Estados Unidos foram marcadas por conflitos de diversa índole. Entre eles, é válido destacar os decorrentes do não reconhecimento das autoridades mexicanas de turno por seu vizinho do norte e os vinculados a interesses econômicos, em especial os das empresas petroleiras norte-americanas. Com o propósito de combater a contrapropaganda ianque, o governo do general Obregón (1921) promove uma série de ações orientadas à divulgação de uma imagem positiva do México no exterior (filmes documentais, conferências, etc.). $\mathrm{O}$ período coincide com o crescimento do país como mercado consumidor de filmes estadunidenses (segundo Aurelio de los Reyes (1993. p. 177), México se torna o mercado mais importante da América Latina, deslocando a Argentina e o Brasil, no decorrer de 1921). Nesse cenário, ciente da força que lhe confere a paulatina pacificação interna e a abertura do mercado cinematográfico mexicano, Obregón decide adotar medidas contra os produtores de fitas que denigrem a imagem nacional. Em 1922, o governo envia uma primeira circular ao cônsul mexicano em Nova York, repassada depois a outros cônsules, autorizando-os a denunciar frente à Secretaria de Relações Exteriores aquelas fitas que considerassem ofensivas. No mesmo ano, Her Husband's Trade Mark (1922), com Gloria Swanson, suscita a cólera do governo mexicano (o filme, provavelmente rodado no México, mostrava a irrupção de uma gangue de ladrões mexicanos na residência da protagonista, com o intuito de violá-la). Apesar do telegrama enviado por Players-Lasky notificando a retirada de circulação do filme, o conflito se acirra. De fato, Lasky muda alguns letreiros, mas continua distribuindo a fita. Em abril de 1922, Obregón proíbe a entrada no país de todas as fitas da Paramount até que Her Husband's Trade Mark seja retirada de circulação em nível mundial. São proibidas também durante esse período diversas fitas das produtoras Aywon Films e Metro Pictures. As altercações continuam até pelo menos 1923, mas geram simultaneamente uma série de ações e de gestos que visam paliar a situação: viagens de astros e estrelas ao México, promessas de esforços no sentido de retratar de forma fiel e favorável o país, reuniões entre produtores estadunidenses e representantes governamentais mexicanos, etc. As recorrentes manifestações de simpatia registradas nas crônicas de Noriega Hope devem ser compreendidas no interior desse contexto. Sobre essa questão, cf. Reyes, Aurelio (1993. p. 98-208).
} 
que sejam somente umas linhas. Mas faça isso. E, sem mais palavras, me conduziu até uma construção distante...

- Senhor, eu queria contar-lhe minha história porque preciso de um pouco de publicidade.

Devo explicar essa frase. A publicidade nos studios norte-americanos mede-se milimetricamente. As atrizes consagradas "ganham" artigos e mais artigos que se distribuem em todos os jornais americanos, mas as que começam não recebem uma só linha dos escrevinhadores, e, como metade do sucesso depende do papel impresso, elas não têm oportunidades de galgar até o topo. Por isso... pedem ansiosamente publicidade como uma esmola.

Essa menina me pareceu uma louca que "posava" para que eu a admirasse e, em consequência, lhe "desse um pouco de publicidade", fosse no México, na Conchinchina ou em Indostão.

- Sou a única atriz que veio a pé de Seattle a Los Angeles, com o único objetivo de se dedicar ao cinema. Tinha dinheiro para a passagem, mas preferi caminhar com o objetivo de chamar a atenção e de ter, nos jornais, "um pouco de publicidade". Meu nome é Ruby e ganho sete dólares ao dia" (1921, p. 130-31).

Ao regressar a seu país de origem, Noriega escreve várias narrativas de tema cinematográfico, publicadas na imprensa periódica e reeditadas mais tarde em dois livros que reúnem a quase totalidade de seus contos: La inútil curiosidad (1923); Miss Patsy y otros relatos (sem data). De alguma forma, a viagem continua. O veículo, agora, é a folha de papel, espaço no qual se realiza uma série de operações com respeito à matéria-prima das crônicas. Por um lado, operações de resgate e de importação, visto que anedotas (como a acima citada), tópicos e registros discursivos (em especial, o da crítica cinematográfica) migrarão para os contos. Por outro lado, também surgem operações transformadoras que alteram pesos, medidas, proporções e modificam o estatuto do narrado, visto que o "horrível", porém "pequeno" e, nesse sentido, secundário no discurso do repórter, se torna o núcleo de uma produção de contos que foca uma e outra vez aqueles que habitam na periferia do star system. O que era a margem nas crônicas se torna centro na ficção.

Entre os textos ficcionais que refazem o caminho de ida e volta à meca holywoodiana, Che Ferrati, inventor, ocupa um lugar de destaque. Motivos literários tradicionais aos quais o cinema confere um novo impulso, como o do duplo ${ }^{(s)}$, clichês consolidados ou em vias de consolidação comparecem nessa narrativa cuja estrutura é bastante próxima à da comédia de confusões, mas que recorre à comicidade com propósitos sérios.

(8) Com diversas inflexões, este tópico se faz presente em vários relatos da época, entre os quais podem mencionar-se $E l$ vampiro (1927), do uruguaio Horacio Quiroga, El hombre que se parecía a Adolfo Menjou (1929), da peruana María Wiesse, Estrella doble (1935), do mexicano José Martínez Sotomayor. 
Inicia o relato com a chegada a Los Angeles do jovem ator mexicano Federico Granados. Sua bagagem são "500 dólares no bolso e um capital de ilusões" (17). Um "pobre diabo" a mais acaba de ingressar na corte dos que perambulam por studios e produtoras em busca de uma oportunidade, melhor ainda, "da oportunidade"; um pobre diabo a mais, candidato a eternizar essa espera nos sets "vestindo-se um dia de cowboy e outro de cidadão romano" $(17)^{(9)}$. Duas semanas depois da chegada, dá-se o encontro fortuito com uma garota não muito diferente da Ruby entrevistada por Noriega, chamada Hazel Van Buren. Essa confessa a Granados tê-lo confundido com "outro cavalheiro, certo fantasmón ${ }^{(10)}$ do cinema, cuja popularidade causava inúmeros estragos nos corações standard de todas as flappers (16); e Hazel, claro, é uma delas ${ }^{(11)}$. O episódio constitui ao mesmo tempo um jogo elementar de sedução travestido de indiferença e um indício, pois Federico Granados se assemelha de fato a um astro que se tornará ipsis litteris um fantasmón ao morrer em plena rodagem e ao qual Granados substituirá, primeiro nessa fita inacabada e depois em outra e em outra... até se transformar num duplo em caráter permanente. Mas o episódio configura, sobretudo, a primeira situação na qual várias personagens assumem atitudes que, por sua vez, imitam e duplicam as da tela, pois é na sala escura onde muitos deles apreenderam seus papéis: os da vida "sonhada" e os da vida "real" — impossível discerni-los.

Esse fenômeno favorece uma profusa circulação de lugares-comuns, de clichês e de estereótipos submetidos a bem humorados jogos de mise en scène ao longo do texto. Refiro alguns exemplos. No primeiro, a confusão da qual é objeto Granados no episódio inicial suscita, por parte deste, as seguintes considerações:

(Ela) o confundira! E, portanto, ao saber que era mexicano, Hazel Van Buren fez um pequeno gesto de nojo (Federico Granados acreditou que era um gesto de ódio, mas na verdade não ia além do santo temor à sujeira). Não voltou a sorrir até que Federico Granados mostrou seus dentes limpos e sua boca sensual, com um sorriso amável, de bom nativo. Hazel imaginou de imediato um romance a la Mary Roberts Rinehart, ao pensar que Federico tinha sangue espanhol, "como Tony Moreno". Podia ser um bom "herói da vida real", porque havia nascido entre touradas, flores, sol ardente e estocadas nas ruas...

Federico ia protestar contra esse falso conceito. Espanha não era a Spain sonhada pelas meninas loiras e os produtores de cinema. Era outra coisa mais delicada e, graças a Deus, muito mais vulgar. Mas sua malícia o fez pensar nas ideias reinantes na União, que fazem de um "latino" um personagem de outro mundo, fantástico, impossível de ser superado, como apaixonado ardoroso (1923, p. 16).

Utilizando-o em seu favor, o estereótipo do "latino" renderá frutos a Granados, pois a girlnutrirá em poucos dias pelo seu Freddy uma "pequena paixão romântica... uma paixão

(9) Para uma análise comparativa da relação instituída com o cinema por essa família de personagens, a família dos "pobres diabos", tanto no tex to de Noriega aqui analisado quanto em Miss Dorothy Phillips, mi esposa (1921), do uruguaio Horacio Quiroga, cf. Gárate, Miriam V. (2008).

(10) O termo é usado como sinônimo de astro, figura muito conhecida, mas evoca essa segunda significação a partir de uma condição primeira da imagem cinematográfica: a condição ilusória, intangível, fantasmagórica.

(11) A expressão remete a um novo tipo feminino que se populariza durante a década de 20 e no qual se combinam moda, consumo, atitudes de certa ordem: vestidos curtos, cabelo à la garçonne, maquiagem evidente, gosto pelo jazz, consumo de cigarros e de álcool, desprezo pelo comportamento considerado "decente" na época, etc. 
tão pequena como um bombom de chocolate, mas coberta de vários quilos de caramelo" (17). Mas se Granados desempenha com eficácia seu papel de "jovem mexican", o mesmo pode-se dizer da jovem norte-americana, uma flapper que posa de girl inocente aos olhos de seu "dear Freddy" e que corporifica, ademais, o arquétipo da infinita ignorância em relação a quase tudo, em especial, a South America: ${ }^{(12)}$

Uma dessas noites, sempre iguais e sempre nutritivas, Hazel estava mais loquaz que de costume.

- Tenho tanta fome! - exclamava entre bocado e bocado. - Fizeram-nos ficar quatro horas no set, ao ar livre, dançando e berrando como se fôssemos doidas. É um filme sobre a Revolução Francesa, e acho que aparece um senhor com um nome extravagante: Ribespirre ou algo semelhante. O grave é que dançamos seminuas, cobertas apenas com uns panos coloridos e um boné estranho... Ouvi que o diretor nos chamava de sans-culottes... Que significa isso, Freddy?

Freddy, imutável, recordou todo seu Michelet. Do "jogo de pelota” à tremenda atuação da viúva, foram caindo retalhos de glória sobre a carne e as fatias de pão com manteiga. Granados deu vazão à sua eloquência de uma forma agressiva para os clientes silenciosos, que começaram a observá-lo com longos olhares bovinos.

— Bom, dear... Não fale tanto, que parece Bill Sunday — interrompeu Hazel, alarmada diante daquela torrente sonora, interminável e majestosa como uma catarata. Mas sua intuição feminina lhe fez compreender, apenas ao olhar o rosto de Granados, que havia matado uma ilusão... E acrescentou docemente:

— Quantas coisas você sabe, amigo Freddy!... E eu que achava que no México ninguém sabia ler... (1923. p. 20)

Uma personagem peculiar nessa galeria de tipos modelados a partir de traços que a própria cinematografia põe em circulação por volta desses anos é Ferrati, que dá título ao relato de Noriega; um argentino fura-vidas, verborrágico, com pretensões de filósofo. Nesse caso, trata-se de uma figura construída a partir de um sistema de referências misto do qual participa o cinema, mas que privilegia principalmente a literatura, em particular, o teatro realista de Florencio Sánchez (há uma menção explícita a $M^{\prime}$ hijo el dotor) ${ }^{(15)}$ e um difuso imaginário de prosápia "gauchesca" no qual se sucedem a vasta planura, o chimarrão, os crepúsculos do sul, a adolescência de Ferrati em Buenos Aires (para onde seu pai o enviara para que retornasse ao lar transformado em dotor), os descaminhos de uma "alma escrava da imaginação e dada às invenções (como a de um fracassado aparelho elétrico destinado a

(12) O uso de palavras ou expressões inglesas destacadas em itálico é muito frequente no relato; daí a utilização na presente análise.

(13) Florencio Sánchez (Montevidéu, 1875 ; Milão, 1910). Jornalista e dramaturgo, autor de numerosas peças que retratam conflitos contemporâneos ao autor, em especial os decorrentes do rápido processo de modernização da região rioplatense. Suas obras dialogam com o denominado teatro criollo, filiado à tradição gauchesca, mas se afastam do mesmo por dar um tratamento mais realista às personagens e às situações, bem como pelo fato de privilegiar o presente enquanto núcleo temático. Sua peça de estreia, M’hijo el dotor, foi representada no teatro La Comedia, de Buenos Aires, em 1903, e obteve sucesso imediato. Nela se confrontam duas gerações: o pai, camponês, sem instrução; o filho, citadino, ilustrado, defensor da vida moderna. Outros títulos importantes são La gringa (1904), Barranca abajo (1905), El desalojo (1906). 
provocar chuva, digno de alguns personagens de Arlt), a decisão de emigrar para essa terra na qual "as ideias valem mais do que os títulos", os primeiros meses nos Estados Unidos (período no qual Ferrati se torna secretário de um rico comerciante de Maracaibo ao qual rouba um bom dinheiro numa noite de festa), sua incursão no cinema como figurante em troca de 5 dólares diários e, finalmente, num retorno ao presente da história narrada, a invenção do "set em miniatura" que possibilita à Superb Picture poupar 100 mil dólares e determina a súbita escalada de Ferrati ao posto de diretor artístico ${ }^{(14)}$. Artífice de truques geradores de ilusão (e de dividendos), o argentino Ferrati e a nova invenção à qual consagra seus esforços naquele momento - uma "pomada maleável, que pode ser modelada sobre os rostos" (20) - desempenharão de imediato um papel decisivo na aventura protagonizada por Granados.

Delineadas as personagens e as situações-marco, o relato se volta ao mundo das sombras "visto por dentro", para recorrer à expressão-título das crônicas de Noriega. Processo que se concretiza desdobrando na ficção um conjunto de situações funcionais do ponto de vista narrativo, mas que possibilitam intercalar um sem número de considerações críticas acerca das condições laborais dos figurantes, da importância crescente e as boas doses de arbítrio dos diretores consagrados, da assimilação de atores e cineastas europeus pela indústria americana, do papel fundamental dos agentes publicitários na ascensão e queda dos astros, do talento de várias figuras célebres (é nesse ponto que as observações críticas sobre Chaplin, Pola Negri, Valentino, Gloria Swanson, Antonio Moreno, entre outros, são postas na boca de um obscuro figurante escocês, Mc Intyre, trazendo o discurso da crítica cinematográfica para dentro do discurso ficcional). Concluído o retrato desse mundo, o relato envereda para a peripécia central: repentina e inesperadamente surge a chance, tão aguardada por Granados, de abandonar a condição de figurante graças ao novo truque de Ferrati:

Federico Granados estava perplexo... O assunto parecia um argumento de romance policial: naquela manhã estava no studio vestido com sua eterna roupa de muçulmano - dois longos meses sem fazer nada! - quando chegou Ferrati, terrivelmente excitado. Tomou-o pelo braço, murmurando palavras incoerentes, e de repente estavam os dois no escritório de Roy Margram, o grande diretor. Ali, com a maior seriedade do mundo, Ferrati assegurou a Roy Magram que o turco que trazia pelo braço não era um muçulmano... mas Henri Le Goffic, que, segundo um telegrama recente, morrera de forma repentina em um vilarejo da montanha. A funesta notícia caíra no studio como uma bomba... Poucas pessoas sabem o que significa para uma empresa cinematográfica a morte de uma estrela. Milhares, ou talvez milhões, de pesos investidos em atores, em sets, em cenário e mise en scène perdem-se irreversivelmente. A fita, com cenas rodadas ao acaso, sem ordem aparente, do início ao fim, não poderá concluir-se nunca... Um desastre!

(14) "Um pouco de engenho, che. Tive a ideia de construir um pequeno set para fotografar em miniatura. Isso foi tudo. Quero dizer que com isso a Superb Picture, em vez de construir um deserto enorme, com oásis e cidades longínquas, apenas fotografou com dupla exposição, sobre minha miniatura, os conjuntos humanos" (19-20). 
Ferrati, ao saber da notícia, teve uma grande ideia. Quase gritou a palavra de Arquimedes e somente suplicou, com a voz tremendo, que se ocultasse a qualquer preço o funesto sucesso. Ele salvaria a Superb Pictures pondo em prática sua última invenção.

Os diretores financeiros olhavam-no perplexos, duvidando da consistência de suas faculdades mentais, e somente Roy Margram, com grande fé, o observava em silêncio. Ferrati correu em busca de Federico e, depois, diante do grupo de magnatas, expôs claramente suas ideias. A morte de Henri Le Goffic já não era irreparável. Henri Le Goffic poderia reencarnar em outra pessoa que tivesse grande semelhança física com o defunto ator francês. Porque Ferrati ia reproduzir, no rosto do substituto, o rosto de Henri Le Goffic. Modelaria as mesmas feições até conseguir uma "duplicação", e para tanto contava com a "Ferratine", a nova pasta obtida em suas experiências.

Os diretores, céticos, moviam a cabeça. Homens práticos, incapazes de sonhar, feitos de realidades, julgavam fantásticas as asseverações de Ferrati... Mas Roy Margram opinou que todos os grandes absurdos haviam acabado, tornando-se grandes realidades. Por que, pois, negar o direito de experimentação a Ferrati, o mesmo Ferrati que obsequiara à Superb Pictures (com) 100 mil dólares graças a uma ideia? (1923, p. 32-3).

De fato, a pomada Ferratine (o artifício técnico, por assim dizer) situa-se numa espécie de encruzilhada na qual parecem confluir, para colidir de imediato, as ilusões de todos: espectadores, figurantes, empresários — estes últimos, os únicos que realizarão seu sonho: o lucro.

O caráter estreitamente imbricado e conflitante dessas ilusões coexistentes será revelado à medida que o leitor se aproximar do desfecho: por um breve intervalo de tempo, Granados acreditará que finalmente se apresenta a chance de sair do anonimato, de elevar-se à condição de protagonista. É verdade que a fortuna parece ter escolhido um caminho bastante sinuoso: para demonstrar sua destreza interpretativa, Granados tem de representar outrem (até aqui, nada de estranho, é precisamente o que faz um ator); tem de representar outrem... representando outro. E, num gesto de ironia redobrada, Noriega faz reconhecer ao diretor Roy Margram que o duplo é muito melhor do que o original, sua atuação é mais versátil. Isso, no entanto, não basta para que Granados se torne alguém, pois seu lugar no sistema já foi estabelecido e é o lugar do outro, embora a preço muito mais baixo.

Nos primeiros dias, a "duplicação" estimulou sua curiosidade e seu humorismo. Ver-se rodeado de várias centenas de figurantes, respeitado por uma multidão de fotógrafos... o fazia sorrir por dentro. Um pobre diabo de 5 dólares semanais transformado num senhor! Ninguém percebera a mistificação.

Roy Margram, astuto como bom inglês, lhe mostrou na tela privada do studio os filmes de Henri Le Goffic. Dessa forma, foi possível copiar todos os movimentos, as expressões, os tiques...

Roy Margram, de sua poltrona, admirava-se diante da versatilidade, da expressão de Granados: 
- Bendito seja Deus! A morte de Le Goffic me enche de um impiedoso gozo, porque acabamos achando um Le Goffic superior...

- Você me enche de alegria, Mr. Margram. E espero que, uma vez acabada esta fita, acabemos com Le Goffic e eu possa trabalhar finalmente com minha alma e com meu corpo para fazer obras-primas.

— Você está enganado, meu pobre amigo. Você, para toda a vida, terá de ser Le Goffic, pois, do contrário, não seria mais, que um simples figurante...

Granados sentiu que o mundo dava voltas ao seu redor. Era um boneco, um fantoche, um duplo para o resto da vida! Teria de carregar Henri Le Goffic para sempre nas costas, como uma maldição. Federico Granados morrera para a arte...

— Mr. Margram, me salve. Eu tenho talento, eu posso tornar-me célebre.

Margram, comovido, respondeu:

— Não sonhe. Você morreu, e, caso se esforce em ressuscitar, os milhões da Superb Pictures voltarão a afundá-lo no túmulo...

Os diretores entraram de repente.

— Mr. Le Goffic - permita-me que o chamemos dessa forma —, viemos parabenizá-lo e tratar de uns enfadonhos assuntos financeiros. Seu sucesso foi enorme, e não é justo que continuemos pagando um salário de 5 dólares diários... Consideramos justo fazer um contrato confidencial... por 150 dólares semanais.

Granados deu um pulo, vermelho de indignação.

— Vocês acham que ignoro qual era o salário de Le Goffic?... 3.500 dólares semanais. $\mathrm{E}$ eu, que sou o próprio artista, vou receber 150 !

Os produtores se surpreenderam. Como ele era o próprio artista? Le Goffic é que era um artista, com muito réclame, um verdadeiro astro, ao passo que "o senhor" fora, até há poucos dias, um simples figurante... Como ia ser o mesmo? Claro que não era.

A discussão se tornou interminável, até que, por fim, convieram, inflexíveis, em conceder a Granados 600 dólares semanais (1923, p. 36-8)

Se houvesse que atribuir uma moral ao episódio, poder-se-ia afirmar que a moral é esta: para a máquina de sonhos, "parteira" de celebridades e de ilusões, ninguém é alguém, todos os sujeitos podem ser intercambiados, trocados, substituídos. É claro que a lógica inerente à maquinaria faz com que nem todos os joões-ninguém valham o mesmo, que uns valham mais e outros menos, segundo as circunstâncias. De qualquer forma, uma coisa é segura: para os empresários, quanto menos custar trocar um joão-ninguém por outro, melhor; e quanto mais joões-ninguém estiverem envolvidos, mais barata, a substituição. 
Do outro lado da tela e fora dos estúdios, na "vida real", a ilusão consoladora de Granados, sua necessidade de ser alguém em algum lugar, termina estilhaçando-se pouco mais tarde contra a frivolidade da girl Hazel Van Buren, na qual depositara erroneamente seus frustrados "desejos de individualização". Com efeito, enquanto a situação vai se complicando para o mexicano - que deve interpretar seu personagem durante mais tempo, dentro e fora dos sets, carregar a cada dia por mais horas sua máscara para satisfazer os editores publicitários e cuja farsa é descoberta pela coprotagonista do filme ao rodar uma cena amorosa com Federico - , enquanto isso ocorre, Granados se consola pensando que, ao menos para sua girl, ele é ele e não o outro, que talvez a chave de sua felicidade resida em revelar o mistério a Hazel. Mas a esperança cai logo por terra: "E se Hazel se apaixonasse mais pelo 'seu' Henry Le Goffic do que pelo seu próprio eu atual? São tão estranhas as mulheres..." (40). Desnecessário dizer que do pensamento ao ato há apenas um passo, que Hazel se sentirá cada vez mais atraída pela imagem do astro e, flapper ao fim e ao cabo, não deixará de aproveitar uma oportunidade que se lhe apresenta em Sunset Boulevard para aproximar-se de Le Goffic/Granados, dirigir-lhe "um sorriso canalha e insinuante" e, não muito depois, enviar uma carta tentando marcar um encontro. Como se não bastasse, Granados recebe um último golpe ao ser informado de que sua mãe se encontra gravemente enferma, fato que o leva a exigir o pagamento do contrato, enviar o dinheiro ao México e aventar a hipótese de suicídio, devido ao insuportável dessa dupla/nula vida.

Ao longo desse processo, os sentimentos de Granados por Ferrati (vaidade satisfeita e salário quintuplicado) mudam de tom. Primeiro, prevalece o rancor, que gera recriminações retrucadas com perspicácia pelo argentino:

— Egoísta e mau amigo!... Você não teve pruridos em me matar, em me fazer perder meu próprio espírito, para ganhar dólares...

Ferrati, dando-lhe tapinhas nas costas, explicou:

- Acalme-se, Federico. Você tem dinheiro, glória, em suma, tudo o que é possível ambicionar. Você já não é mais Federico Granados e sim Henri Le Goffic? Que baboseira... Dá na mesma uma coisa ou outra, tonto. Afinal, ninguém sabe o que seremos amanhã, no túmulo; que importa, então, ser outra coisa em vida? (1923, p. 40).

Pouco depois, no ápice do desespero, Ferrati se torna para Granados uma mescla de testamenteiro, confessor e conselheiro:

Ferrati começou a falar:

— As mulheres não valem a pena, compadre! Matar-se por uma?... Isso seria confessar a derrota de Federico Granados diante de Le Goffic. Apenas uma estúpida maneira de conceder-lhe a satisfação de uma gargalhada de além-túmulo. Não, senhor! ... Devia expulsar a pontapés a flapper, e depois seria necessário lutar contra si mesmo, até conseguir que Le Goffic fosse inferior a Federico Granados. Simples luta espiritual que terminaria, finalmente, com o knock-out do intruso. Que ganharia com o suicídio? Desaparecer do mundo no exato instante em que ia virar milionário. Porque - como já dissera em outra ocasião — dava no mesmo ser uma coisa ou outra(,) se, afinal, em longo prazo, na hora da morte, teríamos de nos transformar de forma definitiva. Ao 
se matar, portanto, ia tornar-se outro, quem sabe o quê? Lesma, flor, árvore ou musgo... (1923, p. 45).

São em passagens como essa que o discurso de Ferrati, mistura de pragmatismo, picardia e "metafísica", evoca a linhagem gauchesca dos Vizcacha ${ }^{(15)}$ ou de outros personagens congêneres. Se nesse jogo ninguém é alguém, se "o mesmo dá ser uma coisa ou outra" porque a identidade de todos foi confiscada e/ou é uma ilusão passageira - fato que a morte corrobora de forma drástica —, melhor ser outro em vida, milionário, segundo prega a moral de Ferrati. O final dessa história? Dissuadido de se suicidar, Granados opta pelo retorno à terrinha de origem:

Federico Granados deixava Los Angeles para trás... Pôs a mão direita no bolso. Apalpou suas notas... e o simples contato com aqueles milhares de dólares infundiram-lhe uma tranquila confiança no porvir. México, seu México, era muito grande. Alguma coisa conseguiria fazer em sua terrinha, sem necessidade de trocar de rosto ou de alma...

E, pela primeira vez, ao cabo de vários meses, Granados teve a sensação de que morrera Le Goffic (1923, p. 49).

Entre a ida e a volta de Granados, os pesos e as medidas se alteraram: na ida, 500 dólares no bolso e um capital de ilusões; no regresso, alguns milhares de dólares capazes de infundir certa confiança no futuro, mas nenhuma ilusão a respeito da máquina de sonhos. Nessa segunda viagem, que revisita na ficção a primeira viagem do cronista, a margem se torna centro e a escrita muda de foco. Ao primeiro plano passam os "pobres diabos".

\section{REFERÊNCIAS BIBLIOGRÁFICAS}

ALMOINA, Helena (org.). Notas para una historia del cine mexicano (1896-1924). México: Filmoteca Unam. v. I e II, 1960, 1980.

BODET, Jaume Torres. La cinta de plata. In: SCHNEIDER, Luis (org.). Crónica cinematográfica. México: UNAM, 1986.

CASANOVA, Manuel Gonzáles (org.). El cine que viófósforo. Alfonso Reyes y Martín Luis Guzmán. México: FCE, 2003.

. Los escritores mexicanos y los inicios del cine. 1896-1907. Culiacán: Unam/El Colegio de Sinaloa, 1995.

GÁRATE, Miriam V. Notas de trabalho sobre Horacio Quiroga. Literatura, cinema, psicanálise: projeções e intersecções de campo. Revista Literatura e Sociedade, USP, n. 10, 2008, p. 170-183, 2008.

Tradição letrada e cinema mudo: em torno a algumas crônicas mexicanas de começos do século XX. Revista Alea, Programa de pós-graduação em Letras Neolatinas, UFRJ, v. 10, n. 2, jul./ dic. 2008.

. Cinema e ficção literária em dois escritores hispano-americanos. Em torno a Horacio Quiroga e Carlos Noriega Hope. Revista Aletria, FALE/UFMG, v. 18, jul./dic. 2008. No prelo.

(15) Personagem do poema canônico Martín Fierro, celebrizado pelo utilitarismo e pela ausência de ética de seus preceitos de vida. 
HOPE, Carlos Noriega. El mundo de las sombras. El cine por fuera y por dentro. México: Andrés Botas e Hijo, 1921.

. La inútil curiosidad. México: Talleres de El Universal Ilustrado, 1923.

. Las experiencias de Miss Patsy y otros cuentos. Puebla: INBA. (s/f).

LEAL, Juan Felipe; BARRAZA, Eduardo; FLORES, Carlos. Anales del cine de México (1895-1911). México: Eón, Voyeur, 2002. v. 7.

LOS, Aurelio Reyes de. Cine y sociedad en México (1896-1930). Vivir de sueños. (1896-1920). México: UNAM, 1981. v. I.

Cine y sociedad en México (1896-1930). Bajo el cielo de México (1920-1924). México: UNAM, 1993. v. II.

MAHUERHOFER, Hugo (1949). A psicologia da experiência cinematográfica. Traducción de Psychology of filme experience, 1966. In: XAVIER, Ismail (org.). A experiência do cinema. Rio de Janeiro: Graal, Embrafilme, 1986.

MIQUEL, Angel (org.). Los exaltados. Antología de escritos sobre cine en periódicos y revistas de la ciudad de México 1896-1929. Guadalajara: Univ. de Guadalajara, 1992.

El nacimiento de una pasión: Luis G. Urbina, primer cronista mexicano de cine. México: UPN, 1995. 1995.

. Por las pantallas. Periodistas del cine mudo. Guadalajara: Universidad de Guadalajara,

Disolvencias. Literatura, cine y radio en México (1900-1950). México: Fondo de Cultura Económica, 2005.

QUIROGA, Horacio. Miss Dorothy Phillips, mi esposa (1921). El vampiro (1927). Todos los cuentos. Edición crítica, Napoleón Baccino Ponce de León y Jorge Laforgue. Colección Archivos, ALLCA XX, 1996.

ROSSET, Climent. Propos sur le cinéma. Paris: Presse Universitaire Française, 2001.

SOTOMAYOR, José Martínez. Estrella doble. 1935. In: Trama de vientos. Cuentos y relatos completos. México: Colección Biblioteca, 1987. v. I.

WIESSE, María. El hombre que se parecía a Adolfo Menjou. Amauta, n. 28, p. 41-7, 1929. 